\title{
The Modeling and Simulation of Proportional Reversing Valve Based on AMESim
}

\author{
Lin Chuang ${ }^{1, \text { a }}$, Fei Ye ${ }^{2, b}$ \\ ${ }^{1-2}$ School of Mechanical Engineering, Shenyang Jianzhu University, No.9, Hunnan East Road, \\ Hunnan New District, Shenyang City, Liaoning, P.R. China, 110168 \\ alinchuang2014@163.com, bfeiye0@sina.com
}

Keywords: AMESim; Proportional Reversing Valve; Modeling and Simulation

\begin{abstract}
In some models of proportional reversing valve as an example, by Ansoft software and AMESim software respectively establishes the finite element analysis model of proportional solenoid and the proportional reversing valve with simulation model, the output characteristic parameters which are obtained by Ansoft software import AMESim proportional solenoid model, setting simulation parameters, comparing theoretical characteristic curve and the sample parameter, to determine the proportional solenoid model is correct.By analyzing the proportional reversing valve model simulation of the proceeds of the pilot valve to control pressure curve and the main valve core displacement curve, known pilot valve for the main valve has good controllability, proportional reversing valve model to meet the corresponding functional requirement, for it can be used in lifting hydraulic circuit simulation model provides an important reference.
\end{abstract}

\section{Introduction}

At present, it is an important means of analysis of the hydraulic system operating characteristics with the help of AMESim simulation, when the software simulates the truck crane hoisting circuit containing the proportional reversing valve, it need the help of HCD function to model the simulation of the proportional reversing valve[1]. Single using HCD to set up the simulation model of the proportional reversing valve,it usually simplifys the proportional electromagnet,uses piecewise function simulation of its drive on valve core according to the sample provided parameters,and is hard to ensure the simulation accuracy.The author attempts to use the finite element analysis software Ansoft Maxwell to model the proportional electromagnet, through the simulation input/output characteristic of proportional electromagnet, as a proportional directional valve AMESim simulation modeling of the input signal,to ensure the accuracy of hydraulic system simulation containing proportional control valve.

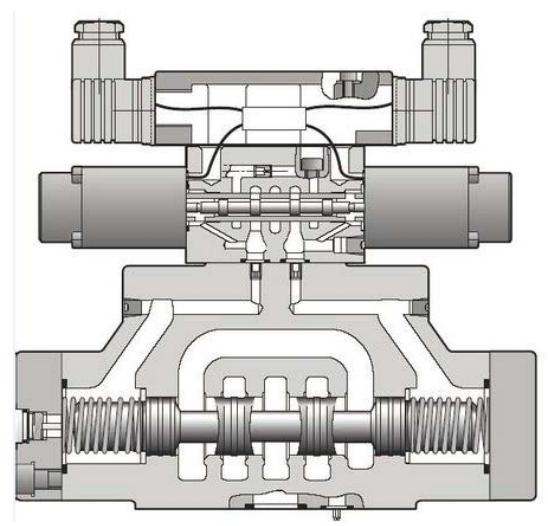

Fig.1 Pilot proportional direction valve structure diagram

This paper is based on the structure and working principle of proportional directional valve, uses AMESim software for modeling and simulation, analysis of the simulation of pilot valve to control 
pressure curve and the main valve core displacement curve, knowing pilot valve for the main valve has good controllability,proportional directional valve model meeting the corresponding functional requirement, is an important reference for it can be used in lifting hydraulic circuit simulation model provides.

\section{The working principle of the proportional directional valve}

Fig. 1 is the structure diagram of the guide type proportional directional valve, this valve is mainly consisting of two parts, proportion of pilot valve and main valve ,the pilot valve's internal structure includes integrated proportional amplifier, proportional electromagnet and the centring spring, etc.Proportional amplifier amplifys the power of the command signal,inputs proportional current to the proportional electromagnet, proportional electromagnetic outputs electromagnetic force and promotes the forerunner in proportion valve core, at this point, generating a control pressure at the outlet of the pilot valve,it pressd on the one end of both sides of the main valve core, under the action of the pressure,main valve core gradually overcomes the force of the reset spring and begins to move, and forming a valve mouth opening, and the oil flow rate can be changed proportionally and the flow direction can be changed,so to realize the control of the position and speed of the actuator.

\section{The proportional electromagnet modeling and simulation}

In order to study the dynamic output characteristics of proportional electromagnet working alone,it is built in the AMESim simulation model as shown in Fig.2, the main part of its proportional electromagnetic valve is composed of signal input, and the quality of block and the reset spring, the quality of block $\mathrm{M}$ is according to the proportional electromagnet armature putting total quality to set, and design of the friction coefficient and reset spring pre-tightening force and stiffness reasonably.

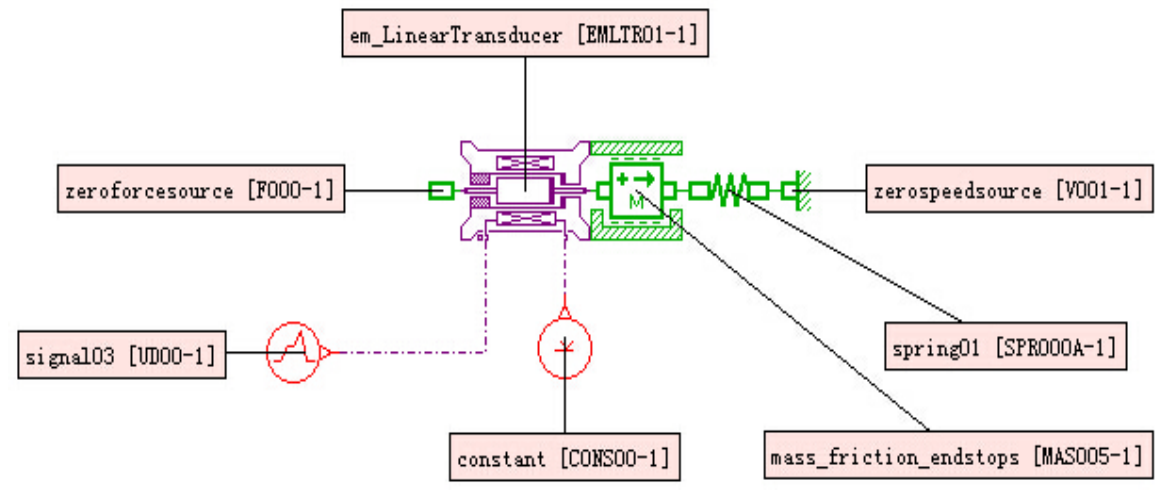

Fig.2 Proportional electromagnet AMESim simulation model

\subsection{AMESim proportional electromagnetic valve is created in the output file}

Proportional electromagnet GH263-060 as sample, the rated current of 1.11[A] and rated travel $4[\mathrm{~mm}]$, suction $145[\mathrm{~N}]^{[2]}$, proportional electromagnetic valve is built by using Ansoft software model, when the input rated current is 1.11[A], steady-state output proportional electromagnet force changes between $137 \sim 161[\mathrm{~N}]$, the mean value of $148.4[\mathrm{~N}], 145[\mathrm{~N}]$ sample value and the error is only $2.3 \%$, the model correctly reflects the proportional electromagnet output characteristic ${ }^{[3]}$.Proportional electromagnetic valve is set up in the AMESim simulation model, need the electromagnetic force and inductance output characteristics as the data support, through AMESim table edit module will Ansoft Maxwell 2D analysis of the proceeds of the proportional electromagnet electromagnetic force and inductance related data, in the form of a 2D table in AMESim are stored for Diancitie. The data and Dianganxin data format file, so that the proportional electromagnet simulation parameters when imported.

3.2 The simulation parameters settings 


\begin{tabular}{|c|c|}
\hline \multicolumn{2}{|c|}{ Table 1 Proportional solenoid simulation parameter Settings } \\
\hline The input signal of voltage & Enter a step signal of $0[\mathrm{~V}]$, after $1[\mathrm{~s}]$ turning to $13[\mathrm{~V}]$ \\
\hline Proportional solenoid & $\begin{array}{l}\text { Internal air gap } 0.4[\mathrm{~mm}], 1350 \text { turns, winding } \\
\text { resistance } 10[\Omega] \text {, the remaining value from the default }\end{array}$ \\
\hline Electromagnetic force data & Import File:Diancitie.data \\
\hline Inductance data & Import File:Dianganxin.data \\
\hline Mass & $\begin{array}{l}\text { Mass } 0.01[\mathrm{~kg}], \text { Viscous friction coefficient } 10[\mathrm{~N} /(\mathrm{m} / \mathrm{s})] \text {, } \\
\text { Displacement limit } 5[\mathrm{~mm}]\end{array}$ \\
\hline Return spring & Preload 15[N],Spring stiffness $10000[\mathrm{~N} / \mathrm{m}]$ \\
\hline Set Solver & Simulation time $1[\mathrm{~s}]$, Interval $0.001[\mathrm{~s}]$ \\
\hline
\end{tabular}

Through to the proportional electromagnet input voltage control signal, proportional electromagnet coil inside an electrical current, electromagnetic loop formation on the armature make its output electromagnetic force, after reaching reset spring pre-tightening force, under the impetus of the armature push-rod spring began to shrink.

In AMESim environment parameter settings, set parameters for the model on the basis of the above conditions, the main parameter such as Table 1.

3.3 Run the simulation

After setting simulation parameters, operation simulation, get proportional electromagnet simulation results are as follows:

(1) The input voltage and current curves

Can be seen from the Fig.3, the input voltage coil is the input voltage proportional solenoid, that is, between 0 and 1 seconds, a linear growth trend, the voltage change range is $0 \sim 13[\mathrm{~V}]$.At this point, as the input voltage, current also increases gradually, in the $1[\mathrm{~s}]$ current peak of $1.104[\mathrm{~A}]$. The numerical samples with proportional electromagnet rated current numerical 1.11[A] very close.

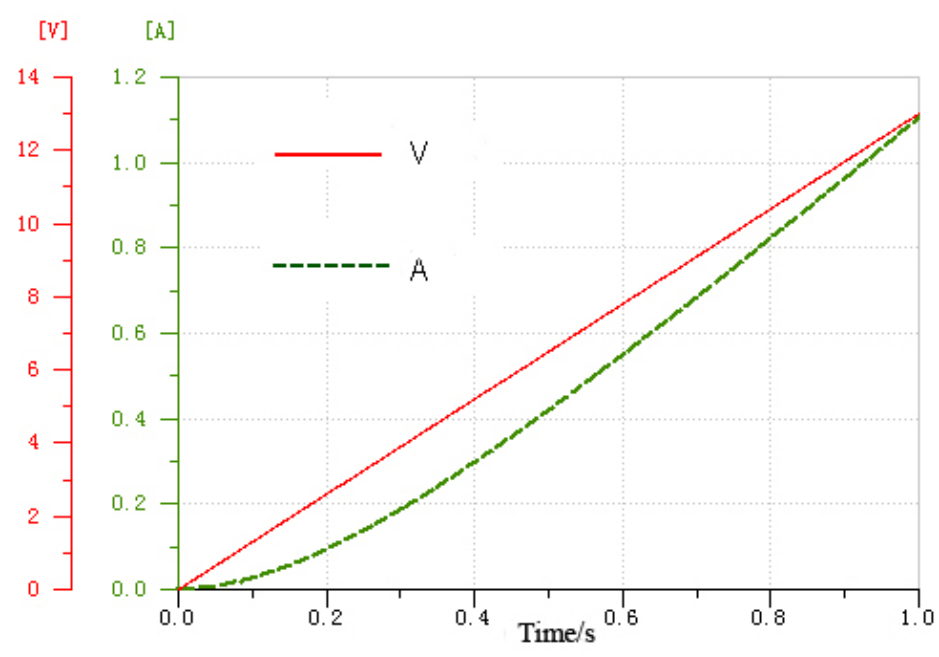

Fig.3 Input voltage and current curve over time

(2) The armature current push rod - force change curves 


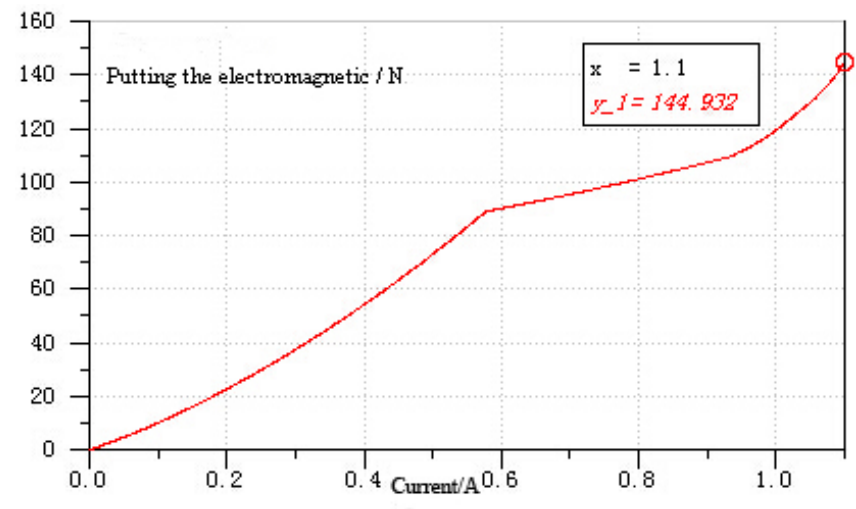

Fig.4 Putting armature current - force characteristic curve

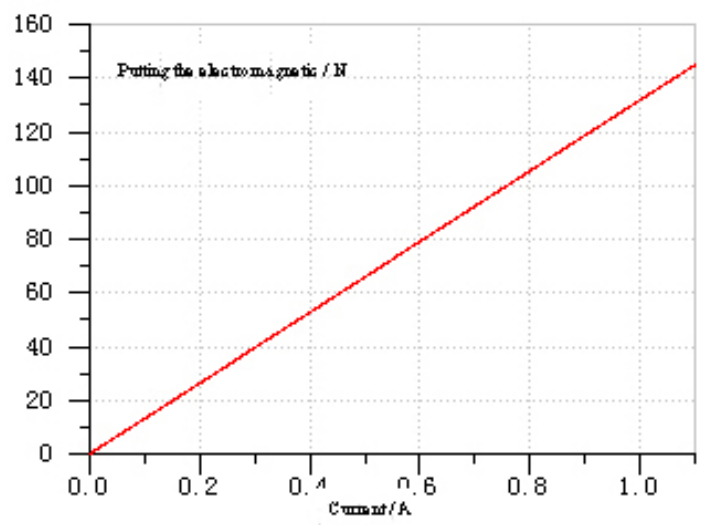

Fig.5 Theoretical curve

Current - power output characteristics of proportional electromagnetic valve is an important index of evaluating its control performance, can be seen in Fig. 4 armature putter output force changing with the current, before $0.58[\mathrm{~A}]$, electromagnetic force approximation to grow by a certain slope, in 0.58 [A] place, putting electromagnetism appeared inflection point, 0.58[A] and 0.93[A] stage, and electromagnetic force in another slope increase slowly, in 1.1[A] output reach maximum electromagnetic force 144.932[N].Electromagnetic force in the middle stage of slow increase of the reason is that when the armature inductance increases after putting a displacement, the obstacles of thrust increases have played a role, with the increase of current, push rod after a certain stage in electromagnetic force increases rapidly, in the end when the current is 1.1[A], putting the output force is $144.932[\mathrm{~N}$ ], the sample value and the proportional electromagnet suction numerical rating $145[\mathrm{~N}$ ] almost unanimously. Armature putter output force rapid rise, slow increase, rapid rise in three stages, and the current proportional electromagnetic valve is shown in Fig.5 - theory of power output characteristic curve, in contrast, the trend and numerical difference is not big, in the range of allowable error.Appear afore-mentioned difference possible factors is: in the process of proportional electromagnet modeling and simulation, to the simplified model, the parameters of the individual module default assumptions, will also introduce a small error ${ }^{[4]}$.

Simulation results in view of the above analysis, the proportional solenoid current - force characteristic curve is close to the theoretical analysis, the curves in its value and sample parameter is very close, so after the proportional electromagnet model can be applied to the study.

\section{The proportional directional valve with the modeling and simulation}

As shown in Fig.6.Using AMESim software model pilot proportional directional valve.

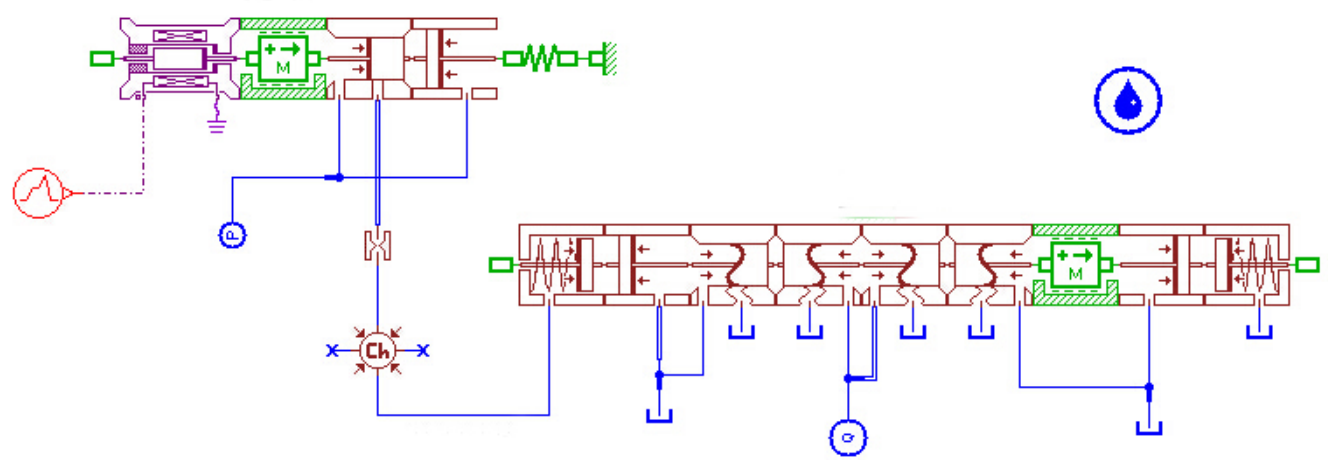

Fig.6 Pilot proportional directional valve with the simulation model

\subsection{The simulation parameters settings}

Pilot valve as the premise of proportional directional valve, the manual input signals accurately convert proportional electromagnet force output signal, and then passed to the control valve core, with the help of drive valve core movement to achieve the goal of controlling the oil is loaded into the main valve core on each control cavity.As drive carrier output proportional electromagnetic valve is 
the whole process, the electromagnetic force, putting through the armature effect on pilot valve core, when the output of the electromagnetic force is greater than the reset spring pre-tightening force, valve core began to move and generate the opening of valve port, control the oil into the left side spring cavity of main valve core, when pressure is enough to overcome the right after the spring pre-tightening force and the valve core friction, the main valve core movement to the right, at the same time in the main valve spool valve mouth opening, realize the main valve reversing throttling.

In AMESim environment parameter settings, according to the proportional electromagnet simulation model and guiding the operation condition of the proportional directional valve set parameters for the model, main parameter such as Table 2.

\begin{tabular}{|c|c|}
\hline \multicolumn{2}{|c|}{ Table 2 Setting the main parameter of Pilot proportional directional valve } \\
\hline Control pressure & Constant Source 30[bar] \\
\hline $\begin{array}{l}\text { Directional valve } \\
\text { spool }\end{array}$ & $\begin{array}{l}\text { Piston diameter } 15[\mathrm{~mm}], \text { Rod diameter } 2[\mathrm{~mm}] \text {,The rest take a default } \\
\text { value }\end{array}$ \\
\hline $\begin{array}{l}\text { The main valve } \\
\text { mass }\end{array}$ & $\begin{array}{l}\text { Mass 0.02[kg], Coefficient of viscous friction } 15[\mathrm{~N} /(\mathrm{m} / \mathrm{s})] \text {,Higher } \\
\text { displacement limit } 15.2[\mathrm{~mm}], \text { The rest take a default value }\end{array}$ \\
\hline $\begin{array}{c}\text { The main valve } \\
\text { spring cavity }\end{array}$ & Pre-tightening force $15[\mathrm{~N}]$, Spring rate $10000[\mathrm{~N} / \mathrm{m}]$ \\
\hline Traffic sources & Constant flow rate $2[\mathrm{~L} / \mathrm{min}]$ \\
\hline Set the solver & Simulation time $1[\mathrm{~s}]$,Time interval $0.001[\mathrm{~s}]$ \\
\hline
\end{tabular}

4.2 Run the simulation

Run the simulation, the curve can be obtained as follows:

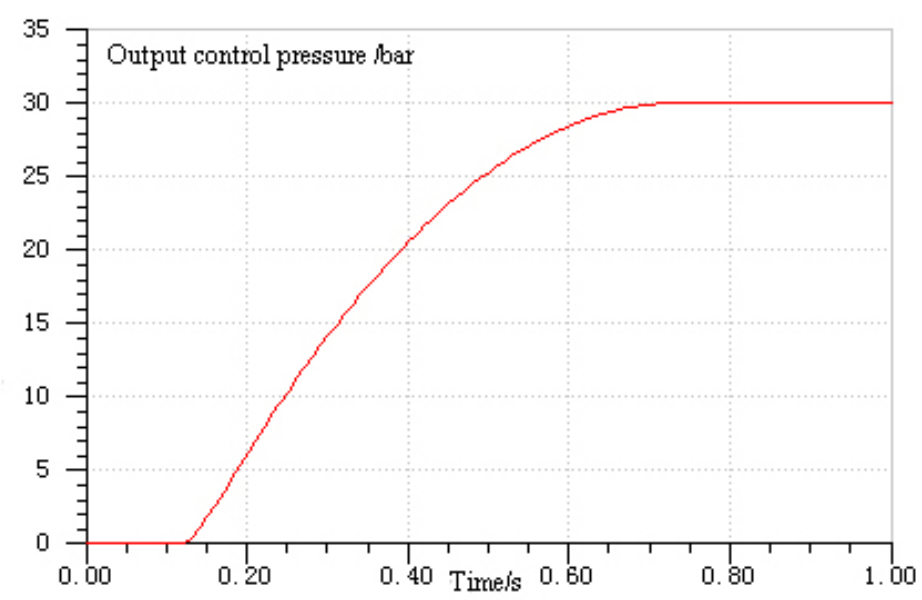

Fig.7 Pilot valve to control pressure curve

Fig.7 is pilot valve to control pressure output curve.Pilot valve control output by the pressure on both sides of the main valve core, under the action of the control pressure, the valve core gradually overcome the role of the reset spring and fluid dynamics, and finally formed the movement of the main valve core, forming a valve mouth opening, the main valve to realize reversing the throttle.By figure, output pressure is 0 [bar] before 0.13 [s], 0.13 [s] control pressure output delay, between $0.13[\mathrm{~s}$ ] to $0.7[\mathrm{~s}$ ] time, control the pressure gradually increased, until 0.7 [s], the output value of the maximum 30 [bar]. 


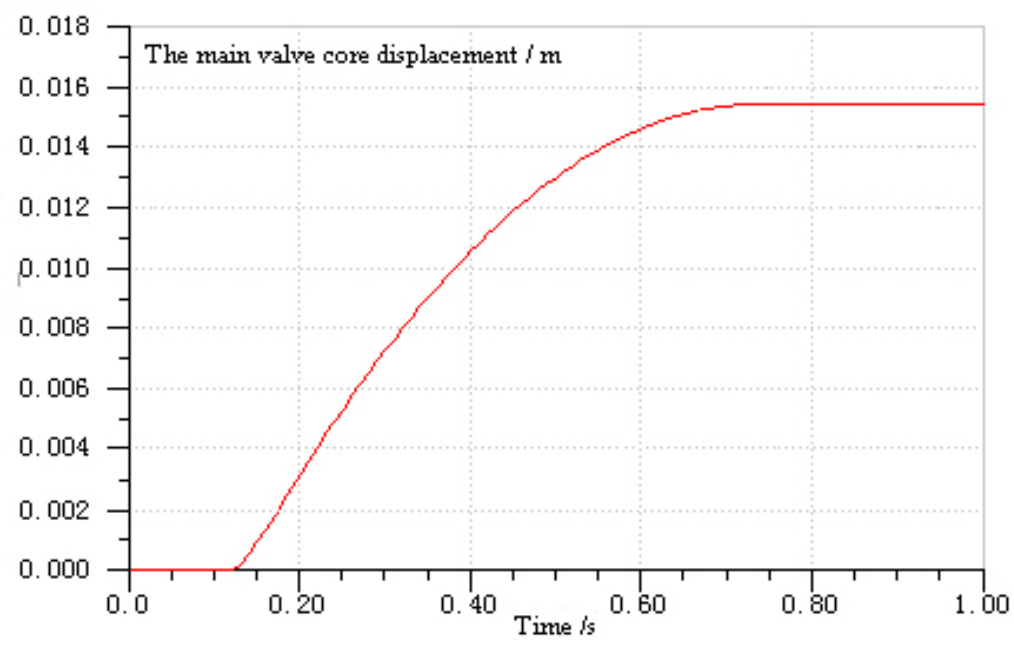

Fig.8 Main valve core displacement curve

The Fig.8 shows that the main valve core displacement curve and pilot control pressure curve trend is consistent, the main valve core did not produce displacement before 0.13 [s], 0.13 [s] to 0.7 [s] in the main valve core control pressure, the maximum displacement of the $15.2[\mathrm{~mm}]$, curve reflects the pilot valve for the main valve with good controllability ${ }^{[5,6]}$.

\section{Summary}

In AMESim environment, the proportional electromagnet about the working current and the clearance between the output force and the inductance data respectively by $2 \mathrm{D}$ table format is converted to the corresponding format file, proportional electromagnetic valve is set up in the AMESim simulation model of the 2D table data import magnet linear converter, the simulation analysis of the dynamic output characteristics in AMESim software, the result of the proceeds of the current - force curve and theoretical curve contrast, verify the validity of the model, for further in-depth theoretical research to provide adequate basis.Set in AMESim model based on proportional electromagnet HCD, pilot proportional directional valve with HCD model, through the analysis of the simulation of the pilot valve to control pressure curve and the main valve core displacement curve, can be the guide valve for the main valve has good controllability, can be used as a directional control valve is used for lifting hydraulic circuit simulation model.

\section{References}

[1] BideauxE, SeavardaS. Pneumatic library for AMESim. Fluid Power system and technology, (1998),p.185-195.

[2] GH263-060 proportional electromagnet samples. http://www.aykaidi.com/.

[3] Roccatelloa, Mancos, Nervegnan. Modeling a variable displacement axial piston pump in a multibody simulation environment [C]. American Society of Mechanical Engineers(ASME), Torino,(2006),p.456-468.

[4] Wong, JY. Theory of Ground Vehicles[M].John Wiley\&Sons, New York, (2001),p.169-174.

[5] Stringer, John. Hydraulic system analysis [J].The Macmillan Pr.Ltd ,1976.

[6] Ying Sun, Ping He, Yun qing Zhang, Li ping Chen. Modeling and Co-simulation of Hydraulic Power Steering System[C]. 2011 Third International Conference on Measuring Technology and Mechatronics Automation. 2011 IEEE:p.595-600. 